\title{
BRINQUEDO: UM CAMINHO PARA A COMPREENSĀO DA CRIANÇA HOSPITALIZADA
}

Margareth Angelo*

ANGELO, M. Brinquedo: um caminho para a compreensão da criança hospitalizada. Rev. Esc. Enf. USP, São Paulo, 19(3):213-223, 1985.

A utilização de brinquedos, em hospitais, é um dos recursos que facilitam a experiência da hospitalização para a criança Além disso, é um valioso instrumento de informação para a equipe de saúde. A autora apresenta um estudo, onde, através da utilização do "brinquedo terapêutico", pode obter elementos para a compreensão das necessidades da criança hospitalizada.

\section{INTRODUÇÃO}

Quando uma criança é hospitalizada, ela não leva apenas um corpo doente; leva também sua família, além de todas as experiências vividas até esse momento. Isto significa que ela tem as mesmas necessidades de uma criança que permanece em casa, adicionadas de outras decorrentes do fato de estar hospitalizada.

Estas necessidades da criança nem sempre têm sido reconhecidas, sobretudo em hospitais, porque alí o objetivo básico é salvar vidas, curar. Felizmente, alguns hospitais vem modificando suas normas, de modo a facilitar, para as crianças, sua permanência no hospital. Ultimamente tem-se visto um aumento na quantidade de brinquedos em hospitais, o que tem sido parte do movimento para tornar os hospitais infantís mais elegres e mais confortáveis. Sabe-se que crianças, particularmente as pequenas, podem ficar gravemente perturbadas pela estada no hospital, sobretudo se esta for longa; isto pode ser parcialmente o resultado da separação dos pais, mas também decorre da atmosfera assustadora do hospital e, é claro, da doença em si.

Uma das maneiras pelas quais a criança se beneficia no hospital é brincando. O brinquedo pode ajudar a fazer o hospital parecer menos hostíl e proporcionar à criança um recurso para fugir a ansiedade causada pela doença e pelas visões estranhas à sua volta.

- Enfermeira. Mestre em Enfermagem. Professor Assistente do Departamento de Enfermagem Materno-Infantil e Psiquiatrica da Escola de Enfermagem da USP - disciplina Enfermagem Pediátrica. 
Para muitas pessoas, o termo "brincar" significa apenas algo pará divertir ou entreter a criança, uma atividade sem importância, para preencher o seu dia. Segundo BROOKS ${ }^{3}$, o brinquedo é o trabalho da criança; com ele ela aprende como ela ocupa a maior parte do seu tempo, o brinquedo lhe proporciona atividade física, estímulo intelectual, socialização, além de servir como vazão para suas emoções.

Cabe salientar que o termo "brinquedo" não se restringe apenas ao nome dado ao objeto utilizado pela criança mas é empregado também para denominar o momento ou situação em que a criança utiliza um objeto ou uma interação com alguém para seu próprio estímulo.

De acordo com PETRILLO \& SANGER 5, o brinquedo no hospital devolve, em parte, aspectos normais da vida diária e previne maiores perturbações. Além disso, proporciona à criança a oportunidade de reorganizar sua vida, diminuindo assim sua ansiedade $e$ dando-lhe um sentido de perspectiva.

Percebe-se também que a pessoa que brinca com a criança torna-se, muitas vezes, a pessoa para a qual a criança corre quando perturbada e assustada pela doença e pelos tratamentos e exames. Com isso, verifica-se que o brinquedo, no hospital, além de função recreativa e educacional, tem também valor terapêutico.

Para AXLINE ${ }^{1}$, a ludoterapia é baseada no fato de que o jogo é o meio natural de auto-expressão da criana; é uma oportunidade dada à criança de se libertar de seus sentimentos e problemas através do brinquedo, do mesmo modo que, em algumas formas de terapia para adultos, o indivíduo resolve suas dificuldades falando. Assim é a terapia com brinquedo, uma técnica psiquiátrica conduzida exclusivamente por por psiquiatras e psicólogos.

Há porém, uma técnica que pode ser utilizada pelos diversos profissionais de saúde, o brinquedo terapêtico. rado para a criança aliviar a ansiedade gerada por experiências atípicas para sua idade, experiências que podem ser ameaçadoras e requerem mais do que brinquedo recreacional para resolver a ansidade associada, de acordo com STEELE ${ }^{6}$.

Para GREEN ${ }^{4}$ o objetivo do brinquedo terapêutico é dar ao observador melhor compreensão das necessidades e sentimentos da criança. Segundo BARTON ${ }^{2}$, através da observação do brinquedo da criança, um observador habilidoso pode inferir significados que a criança é incapaz de verbalizar.

STEELE ${ }^{6}$ enfatiza a necessidade de ser o brinquedo terapêutico proporcionado sempre que uma criança tenha dificuldade em compreender ou lidar com as experiências.

Considerando as idéias apresentadas e o fato de ser reduzido o número de trabalhos existentes sobre brinquedo em hospitais, foi realizado este estudo, com a finalidade de se obterem elementos para a compreensão das crianças hospitalizadas, através do brinquedo terapêutico. 


\section{METODOLOGIA}

Local

O estudo foi realizado em uma clinica pediátrica de um hospital-escola de São Paulo.

\section{População}

A população foi constituida de cinco crianças internadas na referida clínica, as quais foram selecionadas segundo os seguintes critérios:

- faixa etária de 3 a 6 anos.

- tempo de internação superior a uma semana.

\section{Procedimento}

Cada criança foi submetida a uma sessãão não-diretiva de brinquedo, com a duração de 15 minutos.

O material empregado na sessão foi selecionado de modo a que encorajasse a criança a expressar qualquer sentimento intenso sobre sua doença, hospitalização e tratamento, além de possibilitar um brinquedo criativo e imaginativo.

Para tanto, foram escolhidos os seguintes:

- figuras representativas da familia;

- figuras representativas da equipe hospitalar;

- objetos de uso hospitalar;

- objeto de uso doméstico.

A relação total dos brinquedos empregados, encontra-se no Anexo 1.

\section{Descrição do procedimento}

A técnica descrita a seguir obedece a orientações de AXLINE ${ }^{1}$, com o objetivo de possibilitar a criança brincar com inteira liberdade.

- A criança é convidada a brincar.

- O material é apresentado a ela, mas não é identificado.

- São observados e registrados todos os comportamentos manifestados durante a brincadeira.

- O observador atua de maneira não-diretiva, ou seja, não sugere que brinquedos a criança deve usar ou que atividades deve desenvolver. Não reflete o comportamento não-verbal e não tenta explicar o comportamento, nem sugere que a criança esteja falando de si, quando fala do boneco. 
- As perguntas da criança são devolvidas, para que ela mesma tome qualquer decisão.

- O local onde é realizada a sessão, deve ser o mais conveniente para a criança, podendo ser seu próprio leito, mesa da enfermaria ou outro de sua escolha.

- A criança é notificada do limite de duração da brincadeira e de que será avisada assim que este tempo se esgotar.

\section{Análise dos dados}

O conteúdo das verbalizações e ações da criança, durante a sessão, foi analisado com a finalidade de se identificarem os possiveis sentimentos expressos pela criança.

\section{RESULTADOS E COMENTARIOS}

Caracteristicas da população seguir.

A população estudada, apresentava as caracteristicas descritas a

A idade das crianças variou de 3 a 5 anos, assim distribuídas: duas de 3 anos, duas de 4 e uma de 5, todas do sexo masculino. Este pequeno número deve-se ao fato de terem sido apenas estas as crianças em condições de participarem do estudo, no periodo em que o mesmo foi realizado.

As crianças eram portadoras de doença crônica ou de longa duração. Desta maneira, os diagnósticos das crianças foram: três com Leucemia Linfóide Aguda, uma com Pneumopatia a esclarecer e uma com Retocolite Ulcerativa.

A seguir, serão apresentados e discutidos alguns aspectos das sessões, que se encontram descritas, na íntegra, no Anexo 2.

Objetos utilizados pelas criancas durante a sessão

O Quadro I refere-se aos objetos utilizados pelas crianças, com especificação dos selecionados por cada uma delas. 
QUADRO I

Objetas utilizadas pelas criancas

\begin{tabular}{|c|c|c|c|c|c|}
\hline \multirow{2}{*}{ Objeto } & \multicolumn{5}{|c|}{ Orianga } \\
\hline & $\mathbf{C}^{* 1} \mathbf{1}$ & $\mathbf{C 2}$ & C3 & O4 & C5 \\
\hline Seringa & $\mathbf{x}$ & & $\mathbf{x}$ & & \\
\hline Catéter & $\mathbf{x}$ & $\mathbf{x}$ & & & \\
\hline Bonecos & $\mathbf{x}$ & & $\mathbf{x}$ & $\mathbf{x}$ & $\mathbf{x}$ \\
\hline Equipo & $\mathbf{x}$ & $\mathbf{x}$ & & & $\mathbf{x}$ \\
\hline Telefone & & $\mathbf{x}$ & $\mathbf{x}$ & $\mathbf{x}$ & $\mathbf{x}$ \\
\hline Esparadrapo & & $\mathbf{x}$ & & & \\
\hline Frascos de medicamento & & $\mathbf{x}$ & $\mathbf{x}$ & & \\
\hline Aparelho de pressão & & & $\mathbf{x}$ & $\mathbf{x}$ & $\mathbf{x}$ \\
\hline Estetosc6pio & & & $\mathbf{x}$ & $\mathbf{x}$ & $\mathbf{x}$ \\
\hline Algodão & & & $\mathbf{x}$ & & \\
\hline Colher & & & & $\mathbf{x}$ & $\mathbf{x}$ \\
\hline Frasco de soro & & & & $\mathbf{x}$ & $\mathbf{x}$ \\
\hline Gazo & & & & & $\mathbf{x}$ \\
\hline Mamadeira & & & & & $\mathbf{x}$ \\
\hline Prato & & & & & $\mathbf{x}$ \\
\hline Copo & & & & & $\mathbf{x}$ \\
\hline
\end{tabular}

C* - Criança

Analisando-se o quadro, verifica-se que houve 2 objetos utilizados pela maioria das crianças (4), que foram os bonecos e o telefone. Os bonecos eram úteis, quando a criança pretendia executar algum procedimento.

Além desses, 3 crianças utilizaram o estetoscópio e o aparelho de pressão. Pode-se dizer que estes objetos significaram para as crianças, uma oportunidade de reproduzirem, brincando, as mesmas situações que experimentaram na realidade, ou, simplesmente, a exploração de um objeto ao qual não tinham acesso, mas que fazia parte de sua vivência no hospital. 
Quanto aos demais objetos, verifica-se que quase todos foram utilizados, exceto a espátula e a colher para medicamento (Anexo 1).

No quadro pode ser verificado, também, o número de objetos utilizados por cada criança, que variou de 4 a 11 .

Estes dados podem indicar que as características do objeto influenciaram a escolha de cada criança, na medida em que vinham de encontro a uma necessidade dela. Daí a importância desse procedimento ser não-diretivo.

\section{Manifestações de comportamento emitidas}

com mais freqüência pelas crianças

Durante a sessão, cada criança utilizou o tempo de maneira diferente (Anexo 2).

Analisando-se os comportamentos, nota-se que $\mathrm{C} 1, \mathrm{C} 3, \mathrm{C} 4$ e $\mathrm{C} 5$ realizaram procedimentos em bonecas, como se quisessem experimentar algo que viveram ou que presenciaram em outra pessoa.

Já C2 e C3, apenas tocaram em alguns objetos, mas pareciam pouco à vontade diante deles, até mesmo um pouco tensas. A criança C3 parecia preocupada com o soro que tinha instalado no braço, e C2 pareceu-se perturbada ao ver o boneco que representava a figura do médico.

Parece que cada criança, à sua própria maneira, revelou seu foco de ansiedade.

As crianças $\mathrm{C} 1, \mathrm{C} 4$ e $\mathrm{C} 5$ revelaram seus sentimentos sobre injeçôes, soros e exames, repetindo-os diversas vezes. Já C2 e C3 revelaram seus sentimentos evitando tocar certos materiais.

Verbalizações das crianças durante a sessão

Como pode ser verificado na descrição das sessões, as crianças, durante a brincadeira, falaram muito pouco. C1 falou apenas no final, encerrando a sessão e indicando também o desejo de voltar para casa. C2 e C3 fizeram perguntas sobre os objetos. Além disso, C2 chamou pela mãe, como se não quisesse ficar sozinho naquele momento. $\mathrm{C} 4$, além de fazer algumas perguntas sobre os objetos, utilizou-se de palavras para indicar o que estava pensando ou fazendo. Foi quem mais falou durante a sessão. C5 não disse uma palavra durante a brincadeira. Parecia inteiramente concentrado no que estava fazendo.

A pouca verbalização não prejudicou a expressão de sentimentos. Algumas expressaram-se através de palavras, outras expressaram-se indiretamente, através do silêncio e da tensão aparente diante de certos objetos.

Esta análise sucinta das sessões permitiu compreender que as crianças, diante dos brinquedos, encontraram uma oportunidade para projetar suas vivências. Algumas utilizaram-na e experimentaram diversos pro- 
cedimentos. Tiveram participação ativa na situação. Outras não participaram tão ativamente, mas apenas como podiam fazer naquele momento.

\section{CONSIDERAÇÕES FINAIS}

Apesar de realizado uma única vez, o procedimento utilizado neste estudo mostrou-se efetivo, sobretudo em relação a um aspecto: facilitou o inicio de um relacionamento. Apesar do meu contato com estas crianças ser diário, parece que apenas a partir da sessão de brinquedos é que elas realmente começaram a me perceber. como se através daqueles brinquedos, eu lhes tivesse comunicado meu interesse e profundo respeito por cada uma delas. Tanto que após o procedimento, elas passaram espontaneamente a me procurar para comentar alguma coisa sobre si mesmas ou outras coisas que estivessem percebendo.

Embora o brinquedo, em si, permita à criança exteriorizar sentimentos, isto não é automaticamente acompanhado por mudança em atitudes. Segundo BARTON ${ }^{2}$, a presença de um adulto aceitador, que encoraje a criança a expressar seus sentimentos abertamente, é muitas vezes essencial.

Neste estudo, a brincadeira proporcionou às crianças uma oportunidade de explorarem e experimentarem novos objetos, sensações, atividades e sentimentos, de uma forma não ameaçadora.

Indicou, igualmente, que as crianças doentes também são ativas e exploram e buscam respostas sobre seu mundo. Por isso, necessitam de espaço, tempo e material, não importa o quão simples possam parecer. Elas têm necessidade de participar ativamente, de modo a aprender sobre o mundo no qual estão vivendo.

Neste sentido, a sessão de brinquedos é um excelente recurso, facilmente a disposição da equipe de saúde, sobretudo a de enfermagem, para ajudar a criança a lidar com experências estranhas ou ameaçadoras, ampliando seu campo perceptual e permitindo-lhe exteriorizar seus sentimentos e conflitos. Além disso, as sessōes podem ser um instrumento de valor para a enfermeira, uma vez que possibilitam obter melhor compreensão dos sentimentos e necessidades da criança.

O brinquedo terapêutico não evita que a criança experimente procedimentos dolorosos, mas permite-lhe uma oportunidade para liberar sentimentos de raiva ou hostilidade, provocados pela experiência.

O brinquedo é uma conquista de espaço pela criança.

Brincar é aprender, é estar no mundo. 
ANGELO, M. Play: a way to understand the hospitalized child. Rev. Esc. Enf. USP, São Paulo, 19(3):213-223, 1985.

Play in hospitals is a resource that facilitates the child's experience of hospitalization. Furthermore it is a valiable instrument of information to the health staff. The author presents a study where she can have elements to the comprehension of hospitalized child's needs through therapeutic play.

\section{REFERENCIAS BIBLIOGRAFICAS}

1. AXLINE, V.M. Ludoterapia: a dinâmica interior da crianga. Belo Horizonte, Interlivros, 1972. 351p.

2. BARTON, P.H. Nursing assessment and intervention through play. In: Bergersen, B.S. et ali1. Current concepts in clinical nursing. Saint Louis, Mosby, 1969. p. 203-17.

3. BROOKS, M.M. Why play in the hospital? Nurs. clin. North. Amer., Philadelphia, 5(3): 431-41, Sept. 1970.

4. GREEN, C.S. Understanding children's needs through therapeutic play. Nursing', Jenkintow, $4(10): 31-2$, Oct. 1974.

5. PETRILLO, M. \& SANGER, S. Juego en el hospital. In: - Cuidado emocional del niño hospitalizado. México, La Prensa Medica Mexicane, 1972. p. 111-49.

6. STEELE, S. Concept of communucation. In: - Child health and the family, New York, Masson, 1981. cap 11, p. 710-38. 


\section{ANEXO 1}

Relação dos brinquedos

- Figuras representativas da familla

- mãe

- pai

- menino

- menina

- bebê

- Figuras representativas da equipe hospitalar

- médico

- enfermeira

-- Objetos de uso hospitalar

- seringas

- frasco de soro

- equipo de soro

- catéter

- espátula

- gaze

- rolo de esparadrapo

- bolas de algodão

- frasico de medicamento

- colher para medicamento

- aparelho de pressẽo

- estetoscópio

- Objetos de uso doméstico

- telefone

- prato

- colher

- copo

- mamadeira 


\section{ANEXO 2}

Descriçắo das sessões

$-\mathrm{C} 1$

Idade: 3 anos

Diagnóstico: Leucemia Linfoide Aguda

Pediu para brincar. Experimentou conectar as seringas num catéter, solicitou minha ajuda, visto estar com a mão esquerda imobilizada pelo soro.

Selecionou alguns bonecos. Aplicou o soro na enfermeira e na menina. Aplicou-lhes injeção.

Manuseou seringas e equipos, tentando todas as conexões possiveis.

Deu mamadeira ao menino.

Num dado momento, disse: - Já está bom. Pode levar os brinquedos para outro menino.

Enquanto eu guardava os brinquedos, ele disse: - Tia, eu quero ficar bom logo. Quero ir para casa, ficar com meu irmãozinho.

$-\mathbf{C 2}$

Idade: 3 anos

Diagnóstico: Pneumopatia a esclarecer

Bastante entusiasmado com a idéia de brincar.

Pegou o telefone e disse: - Alô.

Pegou uma boneca e uma colher e deu de comer a ela.

Chamou pela mãe. Esta ficou ao seu lado. Manipulou o telefone prolongadamente. Mostrou as brinquedos à mãe, o frasco de soro e a boneca.

Perguntou o que era, ao pegar um frasco de soro (ele estava recebendo soro, cujo frasco era igual ao que tinha para brincar).

Tocou o estetoscópico e o aparelho de pressão, mas não os pegou.

Olhou bem sério para a figura do médico e pegou outro boneco.

Pediu para acabar. Foi para o colo da mãe.

$-\mathrm{C3}$

idade: 4 anos

Diagnóstico: Leucemia Linfóide Aguda

Mostrou-se bastante contente com a idéia de brincar.

Pegou o telefone e ficou girando o disco. Colocou-o de lado.

Pegou um catéter e perguntou à mãe o que era aquilo. Esta não respondeu, mas ele também não esperou pela respasta.

Pegou o rolo de esparadrapo, a mamadeira e colocou-os de volta na caixa.

Pegou o equipo de soro e olhou para o equipo em seu próprio braço. Tocou novamente o equipo de brinquedo, apertando-o.

Ficou 4 minutos sem tocar em nada, apenas olhando a enfermeira que manipulava o seu soro.

Pegou um frasco de medicamento e ficou batendo-o na perna, manusieando-o. dos.

Comegou a olhar para o ambiente. Não parecia mais interessado nos brinque-

Ficou olhando a enfermeira que manuseava o equipo de outra criança. 
Idade: 4 anos

Diagnóstico: Leucemia Linfóide Aguda

Ficou muito entusiasmado diante dos brinquedos.

Pegou o frasco de medicamento e perguntou: - Isso é de sangue?

Pegou uma seringa e fez movimento e ruído de estar aspirando líquido do vidro. no local.

Pegou uma seringa, encostou-a no próprio rosto e em seguida passou algodão

Saiu para procurar a mãe e voltou em segulda.

Pegou o telefone e disse: - Alo? pode?

Pegou uma boneca, dizendo: - $\mathbf{E}$ igual a de Rosinha. Vou tirar sangue dela,

Dizia: - Nesse braço, agora no outro. (ao mesmo tempo em que aplicava a «injeção» com fôrça em cada braço da boneca e em seguida o algodão).

Pegou o aparelho de pressão e perguntou o que era. Largou-o. Pegou o estetoscópio e disse: - Esse eu sei. Colocou o estetoscópio no ouvido, como que examinando-se. Quis examinar-me também. Deixou-o bastante tempo no ouvido e, ao mesmo tempo pegou uma seringa e algodão, dizendo: - Agora vou tirar sangue.

Largou tudo sobre a mesa, dizendo: - Agora vou procurar minha mãe.

$-\mathrm{C5}$

Idade: 5 anos

Diagnóstico: Retocolite Ulcerativa

Criança sentada na cama, bem encostada à cabeceira, segurando uma pequena tesoura, cabeça baixa.

Não olhou para mim quando perguntei se gostaria de brincar. Apenas balançou a cabeça, indicando que sim.

Abriu a caixa, pegou o estetascópio a colocou-o nos ouvidos, retirando-o logo em seguida. Largou o estetoscópio, pegou o frasco de soro juntamente com o equipo. Pegou uma boneca e fez movimento de instalar o soro nela, no braço esquerdo.

Pegou o estetoscopio e começou a auscultar a boneca, com uma expressăo bastante concentrada no rasto.

Desembrulhou um pacote de gaze. Recolocou o equipo de soro que havia soltado. Retirou-o e enxugou o braço da boneca com a gaze.

Pegou a mamadeira. Aplicou-a na boca da boneca com bastante força. Deu-lhe comida, utilizando-se do prato e da colher. Encheu o copo, usando a mamadeira.

Pegou o aparelho de pressãa, adaptou-o ao braço da boneca juntamente com o estetosicópio. Colocou-os de lado e também a boneca. Pegou outra boneca e instalou o soro.

Pegou o telefone e fez como se o utilizasse, sem emitir qualquer som. Largou o frasco, o telefone a a boneca.

Pegou a tesoura da sua mesa. Guardou os brinquedos na caixa e afastou-os de si, indicando já haver terminado.

Quando me despedi dele, olhou para mim, sorriu e disse «Tchau». 